\title{
Rate of detection of serrated lesions at colonoscopy in an average- risk population: a meta-analysis of 129,001 individuals
}

\section{(ㄷ)(1) $\odot$}

Authors

Junjie Huang*, ${ }^{\text {, }}$ Paul S.F. Chan ${ }^{*},{ }^{1}$, Tiffany W.Y. Pang ${ }^{1}$, Peter Choi ${ }^{1}$, Xiao Chen ${ }^{1}$, Veeleah Lok ${ }^{1}$, Zhi-Jie Zheng ${ }^{2}$, Martin C.S. Wong ${ }^{1,2,3}$

\section{Institutions}

1 The Jockey Club School of Public Health and Primary Care, Faculty of Medicine, Chinese University of Hong Kong, Shatin, Hong Kong SAR, China

2 Department of Global Health, School of Public Health, Peking University, Beijing, China

3 School of Public Health, The Chinese Academy of Medical Science and Peking Union Medical College, Beijing, China

submitted 14.8.2020

accepted after revision $\quad 2.11 .2020$

Bibliography

Endoscopy International Open 2021; 09: E472-E481

DOI 10.1055/a-1333-1776

ISSN 2364-3722

(c) 2021. The Author(s).

This is an open access article published by Thieme under the terms of the Creative Commons Attribution-NonDerivative-NonCommercial License, permitting copying and reproduction so long as the original work is given appropriate credit. Contents may not be used for commecial purposes, or adapted, remixed, transformed or built upon. (https://creativecommons.org/licenses/by-nc-nd/4.0/)

Georg Thieme Verlag KG, Rüdigerstraße 14,

70469 Stuttgart, Germany

Corresponding author

Professor Martin C.S. Wong MD, MPH, Professor, The Jockey Club, School of Public Health and Primary Care, Faculty of Medicine, Chinese University of Hong Kong, 4/F, School of Public Health, Prince of Wales Hospital, Hong Kong SAR, China Fax: +-852-2606-3500 wong_martin@cuhk.edu.hk

\# Supplementary material is available under https://doi.org/10.1055/a-1333-1776

\section{ABSTRACT}

Background and study aims Serrated lesions are precursors of approximately one-third of colorectal cancers (CRCs). Information on their detection rate was lacking as an important reference for CRC screening. This study was a systematic review and meta-analysis to determine the overall detection rate for serrated lesions and their subtypes in average-risk populations undergoing CRC screening with colonoscopy.

Patient and methods MEDLINE and Embase were searched to identify population-based studies that reported the detection rate for serrated lesions. Studies on averagerisk populations using colonoscopy as a screening tool were included. Metaprop was applied to model within-study variability by binomial distribution, and Freeman-Tukey Double Arcsine Transformation was adopted to stabilise the variances. The detection rate was presented in proportions using random-effects models.

Results In total, 17 studies involving 129,001 average-risk individuals were included. The overall detection rates for serrated lesions $(19.0 \%, 95 \% \mathrm{Cl}=15.3 \%-23.0 \%)$, sessile serrated polyps $(2.5 \%, 95 \% \mathrm{Cl}=1.5 \%-3.8 \%)$, and traditional serrated adenomas $(0.3 \%, 95 \% \mathrm{Cl}=0.1 \%-0.8 \%)$ were estimated. Subgroup analysis indicated a higher detection rate for serrated lesions among males (22.0\%) than females (14.0\%), and Caucasians (25.9\%) than Asians (14.6\%). The detection rate for sessile serrated polyps was also higher among Caucasians (2.9\%) than Asians (0.7\%).

Conclusions This study determined the overall detection rate for serrated lesions and their different subtypes. The pooled detection rate estimates can be used as a reference for establishing CRC screening programs. Future studies may evaluate the independent factors associated with the presence of serrated lesions during colonoscopy to enhance their rate of detection.

\section{Introduction}

Colorectal cancer (CRC) is the third most commonly diagnosed cancer and the second leading cause of cancer mortality worldwide, accounting for 1.8 million new cases and approximately

* These authors contributed equally 
polyps over the course of many years, and detection and resection of these lesions reduce both its morbidity and mortality [2]. In the past two decades, the use of colonoscopy for screening has been shown to increase steadily [3]. Although there is evidence supporting the effectiveness of colonoscopy in reducing CRC-related mortality, a certain proportion of screening participants may have interval cancers, defined as those diagnosed between screening and the next post-screening surveillance examinations [4].

In past decades, endoscopists tended to resect adenomas during colonoscopy because adenomas were historically considered as the only type of malignant polyp [5]. Nevertheless, recent studies have suggested that serrated lesions are also precursors of CRC [6]. Approximately $15 \%$ to $35 \%$ of CRCs can be accounted for by this serrated pathway [7]. According to the World Health Organization (WHO), serrated lesions are classified into three types: hyperplastic polyps, sessile serrated polyps (SSPs), and traditional serrated adenomas (TSAs) [8]. Recently, WHO has recommended using the term sessile serrated lesions for SSPs [9].

Although there increasing knowledge about histological categorization of serrated lesions, the detection rate is highly variable [10]. For instance, several studies reported that the detection rate for serrated lesions was between $1 \%$ and $20 \%$ in the proximal colon [11-13]. serrated lesions, especially located in the proximal colon, are usually flat and covered with a mucus cap. They can be dismissed as "benign" HPs by some colonoscopists or they may be difficult to see during endoscopy [14]. Owing to the difficulties in diagnosing serrated lesions during colonoscopy, the detection rate is highly variable among endoscopists. For pathologists, interobserver agreement was only moderate to low in diagnosis of SL subtypes [15]. Information on prevalence will offer an important reference to establish a standard detection rate or indicators of serrated lesions for various population subgroups. This study was a systematic review and meta-analysis to determine the overall detection rate for serrated lesions and their subtypes. It examined whether detection rates differ by gender, anatomical location, or ethnicity and explored potential factors that may affect detection rates in the average-risk population undergoing CRC screening.

\section{Patients and methods}

This systematic review and meta-analysis was conducted according to a pre-registered protocol in PROSPERO (CRD42019133940) and the PRISMA guideline [16]. MEDLINE and Embase on Ovid were searched for population-based, epidemiological studies reporting the detection rate for serrated lesions using colonoscopy as an initial screening tool from their inception to $1^{\text {st }}$ March 2019 without language restrictions. A predetermined search strategy (Supplementary Table 1) was used to search the literature. A multidisciplinary group conducted the systematic review with PSFC and TWYP as reviewers. Consensus was reached by referral to a third reviewer $(J \mathrm{H})$ when there was disagreement. XC further verified the accuracy for all data. All authors had access to the study data and reviewed and approved the final manuscript.

\section{Study selection}

All search results were screened by title and abstract first, followed by full text if relevant. Studies included: (1) investigated asymptomatic individuals undertaking first-time CRC screening; (2) used colonoscopy as an initial screening test; and (3) presented data on the overall, age- or sex-specific detection rate for serrated lesions, SSPs, or TSAs. Abstracts in the initial screening stage were excluded if they: (1) included participants receiving surveillance colonoscopy; (2) did not use a population-based study design, which was defined as those that involved most residents in a specific region as the sampling frame; (3) only reported disease cases with serrated polyposis syndrome; or (4) did not investigate the detection rate for serrated lesions, SSPs, or TSAs or did not report original data. Eligible abstracts were selected for full-text screening.

\section{Data extraction and quality assessment}

Basic information collected from the individual studies included the first author, publication year, study characteristics such as study period, region where subjects were recruited, study design (cross-sectional or cohort), study setting (national screening program, multi-center or single-center study), detection methods, definitions of serrated lesions, settings of screening (routine or surveillance), and participant characteristics (gender ratio, age, ethnicity, smoking status of the study participants). Outcome variables included sample size, case number of serrated lesions and their subtypes, detection rate for serrated lesions, and the age- or sex-specific information on the above variables. The Newcastle-Ottawa-Quality Assessment Scale (NOS), which has been recognized as a useful tool for measuring quality in meta-analyses, was used to assess the quality of each included study by two researchers (PSFC and TWYP) independently [17]. The scale was modified in an attempt to fit our study design, consisting of six dimensions with a total score of eight points $[18,19]$. The six dimensions were as follows: (1) representativeness of the sample; (2) ascertainment of the family history; (3) ascertainment of the outcome; (4) ascertainment of the outcome for quality control; (5) presence of age- or sex specific information on detection rate; and (6) presence of stratified data by any additional stratified variables. One point each was assigned to dimensions 1 to 4 , and two points each were assigned to dimensions 5 and 6 .

\section{Data synthesis and analysis}

A systematic, analytical method was used to calculate the pooled detection rate for serrated lesions from all included studies. The command "metaprop" was adopted to conduct the meta-analysis of rates to generate pooled estimates with exact binomial and score test-based confidence intervals (Cls) [20]. The method provided appropriate ways of combining rates close to the margins by using the Freeman-Tukey Double Arcsine Transformation to stabilize the variances [20]. A random-effects model was used to pool the detection rate for serrated lesions with proportions and $95 \%$ confidence intervals (Cls). Heterogeneity was assessed using Cochran's Q test and $\mathrm{I}^{2}$ statistic. $P=0.05$ was adopted to indicate the statistical sig- 
nificance. $I^{2}>50 \%$ referred to substantial heterogeneity and in such circumstances the causes of heterogeneity were investigated. Subgroup analyses by gender, ethnicity, anatomical location and subtype of serrated lesions were performed to address heterogeneity. $P$ values in subgroup tests were generated by examining the heterogeneity of the results between different groups. Multivariate regression analyses by study quality, definition of serrated lesions, proportions of smokers, firsttime screening participants, and those with previous history of polypectomy were also conducted to further explore the possible sources of heterogeneity. We performed sensitivity analysis by excluding each study and pooling the results. Publication bias was evaluated by Begg's funnel plot with a significant $P=$ 0.05 . Choropleth maps, maps patterned in proportion to the measurement of the statistical variable being displayed, were created to show the overall estimated detection rate for serrated lesions in different countries. All statistical analyses were conducted and graphics created using Stata version 14.0 (College Station, Texas, United States) and R version 3.3.2 (R Core Team).

\section{Results}

\section{Identification of studies}

The PRISMA flowchart of the selected studies is presented in - Fig. 1. The initial search retrieved a total of 10,420 studies. Additional records were searched by referring to the reference lists of eligible papers $(n=16)$. After removing duplicates and screening titles and abstracts, 86 articles fulfilled the criteria for full-text review. After going through the full texts, 69 articles were excluded, as they: (1) reported irrelevant information ( $n=69$ ); (2) recruited high-risk participants or did not report whether the screening participants were asymptomatic $(n=3)$; or (3) did not include adequate information to estimate the detection rates $(n=2)$. Finally, 17 studies met the selection criteria $[10,11,13-15,21-32]$.

\section{Information of included studies}

The characteristics of included studies are shown in $>$ Table 1. The studies were conducted in East Asia $(n=6)$, North America $(n=6)$ and Europe $(n=5)$. The study participants were Caucasians $(n=10)$, Asians $(n=6)$ and a combination of them $(n=1)$. The data collection period for the studies ranged from 1996 to 2014 while the sample size of each study ranged from 926 to 35,126 . The publication years ranged from 2010 to 2017. All studies were cross-sectional with nine being single-center and eight being multicenter studies. All studies used colonoscopy as a screening tool in asymptomatic individuals. For diagnosis of serrated lesion, most studies adopted the WHO criteria ( $n=$ 13) although it was not referenced in other studies $(n=4)$. Twelve studies provided definitions of proximal colon. In 10 studies, it was defined as proximal to the splenic flexure and in two as proximal to the transverse colon. The detection rate for serrated lesions, SSPs and TSAs reported in various studies was $11.3 \%$ to $27.2 \%, 0.5 \%$ to $8.2 \%$, and $0.1 \%$ to $0.8 \%$, respectively. The detection rate at multiple time points was reported for the United States $(n=6,1996-2013)$, South Korea $(n=4,2002-$

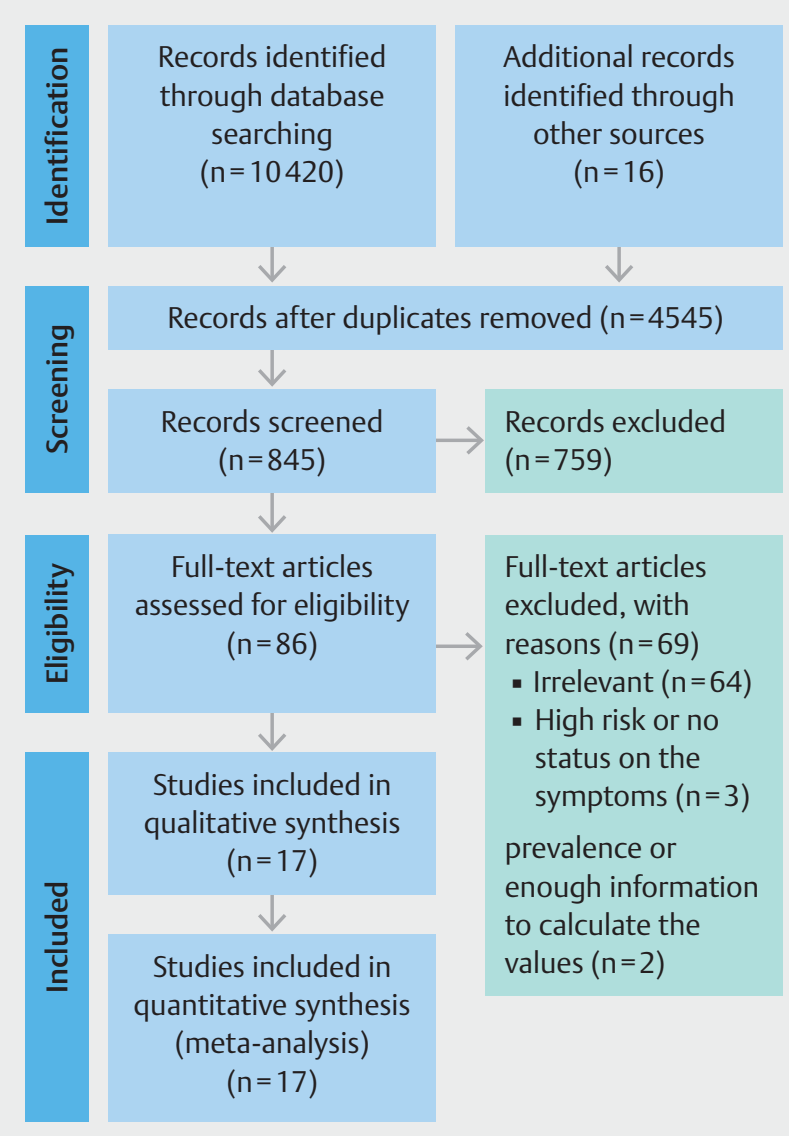

-Fig. 1 PRISMA flow diagram. From: Moher D, Liberati A, Tetzlaff J, Altman DG, The PRISMA Group (2009). Preferred Reporting Items for Systematic Reviews and Meta-Analyses: The PRISMA Statement. PLoS Med 6 (7): e1000097. doi:10.1371/journal.pmed1000097

2012), and the Netherlands ( $n=3,2009-2010)$. For the detection rate for serrated lesions, the United States, South Korea, and the Netherlands had ranges between $13.0 \%$ and $20.6 \%$, $11.3 \%$ and $15.1 \%$, and $12.3 \%$ to $27.2 \%$, respectively. For SSPs, the detection rate was lower in the United States $(11.7 \%)$ than in South Korea (14.7\%) and the Netherlands (12.7\%-23.8\%). For TSAs, the detection rate was relatively low in all three countries $(0.1 \%-0.6 \%)$.

\section{Quality assessment of included studies}

Quality assessment of included studies is shown in $>$ Table 2. The overall quality of the included studies was high, and most of them performed independent validation in the diagnosis of serrated lesions. The majority of the articles (14/17) had an NOS score $\geq 5$. Most of the studies (14/17) had ascertainment of the exposure while all (17/17) had ascertainment of the outcome with additional reports on the quality of colonoscopy (14/ 17). In addition, most studies (13/17) presented additional stratified variables (e.g. anatomical locations and screening year) other than age and gender. 
- Table 1a Characteristics of included studies $(\mathrm{N}=17)$.

\begin{tabular}{|c|c|c|c|c|c|c|c|c|}
\hline Study & Region & State/city & $\begin{array}{l}\text { Study } \\
\text { type }\end{array}$ & $\begin{array}{l}\text { Data } \\
\text { collection }\end{array}$ & Ethnicity & $\begin{array}{l}\text { Sample } \\
\text { size }\end{array}$ & $\begin{array}{l}\text { Male propor- } \\
\text { tion (\%) }\end{array}$ & $\begin{array}{l}\text { Mean age/ } \\
\text { (age range) }\end{array}$ \\
\hline Liang 2012 & USA & Cleveland & 1 & 1996-2006 & Caucasians & 18,003 & 56.1 & 61.4 \\
\hline Kahi 2011 & USA & Indiana & 1 & $2000-2009$ & Caucasians & 6,681 & 49 & 58.9 \\
\hline Hetzel 2010 & USA & Boston & 1 & 2006-2008 & Caucasians & 7,192 & 44 & 58 \\
\hline $\begin{array}{l}\text { Abdeljaward } \\
2015\end{array}$ & USA & Indiana & 1 & $2005-2012$ & Caucasians & 1,910 & 46.2 & $(\geq 50)$ \\
\hline Sanaka 2014 & USA & Cleveland & 1 & $2008-2009$ & Caucasians & 2,167 & 52 & $(\geq 50)$ \\
\hline Ross 2015 & USA & Texas & 1 & $2010-2013$ & Mixture & 2,833 & 35.4 & $(50-75)$ \\
\hline Руо 2017 & South Korea & Seoul & 1 & $2002-2012$ & Asians & 35,126 & 50.5 & 48.5 \\
\hline Min 2012 & South Korea & $\begin{array}{l}\text { Seoul, Chung- } \\
\text { cheongnam-do }\end{array}$ & 1 & $2007-2008$ & Asians & 926 & 52.1 & $(>45)$ \\
\hline Kim 2014 & South Korea & Seoul & 1 & 2005-2012 & Asians & 28544 & 60.8 & $(22-88)$ \\
\hline Lee 2013 & South Korea & Seoul & 1 & 2011-2012 & Asians & 1,375 & 52.4 & $(>50)$ \\
\hline $\begin{array}{l}\text { Wijkerslooth } \\
2013\end{array}$ & Netherlands & $\begin{array}{l}\text { Amsterdam, } \\
\text { Rotterdam }\end{array}$ & 1 & 2009-2010 & Caucasians & 1,354 & NA & $(50-75)$ \\
\hline $\begin{array}{l}\text { Hazewinkel } \\
2014\end{array}$ & Netherlands & $\begin{array}{l}\text { Amsterdam, } \\
\text { Rotterdam }\end{array}$ & 1 & 2009-2010 & Caucasians & 1426 & 51 & $(50-75)$ \\
\hline Grobbee 2017 & Netherlands & $\begin{array}{l}\text { Amsterdam, } \\
\text { Rotterdam }\end{array}$ & 1 & 2009-2010 & Caucasians & 1,256 & 51 & $(50-75)$ \\
\hline Leung 2012 & Hong Kong & Hong Kong & 1 & $2008-2011$ & Asians & 1,282 & 48.4 & 49.1 \\
\hline Chang 2017 & Taiwan & Taipei & 1 & 2010-2014 & Asians & 6,198 & 51.1 & $(\geq 50)$ \\
\hline Buda 2012 & Italy & Feltre & 1 & $2007-2008$ & Caucasians & 985 & 38 & $(\geq 50)$ \\
\hline Ijspeert 2016 & Poland & NA & 1 & $2009-2012$ & Caucasians & 12361 & NA & $(50-65)$ \\
\hline
\end{tabular}

\section{Detection rate for serrated lesions}

The overall detection rates for serrated lesions $(19.0 \%, 95 \% \mathrm{Cl}$ $=15.3 \%-23.0 \%)$, SSPs $(2.5 \%, 95 \% \mathrm{Cl}=1.5 \%-3.8 \%)$, and TSAs $(0.3 \%, 95 \% \mathrm{Cl}=0.1 \%-0.8 \%)$ are shown in $>$ Fig. 2 , Supplementary Fig. 1, Supplementary Fig. 2, and Supplementary Fig. 3.

Compared according to gender, the detection rate for serrated lesions was higher among males $(22.0 \%, 95 \% \mathrm{Cl}=$ $16.4 \%-28.2 \%)$ than females $(14.0 \%, 95 \% \mathrm{Cl}=8.2 \%-21.0 \%)$ (Supplementary Fig.4), while the detection rate for SSPs was similar between males $(2.9 \%, 95 \% \mathrm{Cl}=1.0 \%-5.7 \%)$ and females (2.4\%, $95 \% \mathrm{Cl}=0.8 \%-4.9 \%$ ) (Supplementary Fig. 5 ). The overall detection rate for serrated lesion in the proximal colon was $8.5 \%(95 \% \mathrm{Cl}=6.8 \%-10.5 \%)$ (Supplementary Fig. 6).

In terms of ethnicity, the overall detection rate for serrated lesion was higher among Caucasians $(25.9 \%, 95 \% \mathrm{Cl}=16.4 \%$ $28.2 \% ; n=4)$ than Asians $(14.6 \%, 95 \% \mathrm{Cl}=11.6 \%-18.2 \% ; n=$ 4) (Supplementary Fig.7). This difference was also observed for SSPs among Caucasians (2.9\%, 95\% Cl=1.5\%-4.7\%) and Asians $(0.7 \%, 95 \% \mathrm{Cl}=0.4 \%-1.2 \%)$. The ethnicity specific data on TSA was not available for the present analysis (Supplementary Fig. 8).
Regionally, the highest detection rate for serrated lesions was reported in the Netherlands (27.2\%) followed by Poland (26.6\%) (Supplementary Fig.9). For SSPs, the Netherlands (3.9\%), the US (2.8\%), and Italy (2.3\%) had higher rates than other regions. In terms of detection rate for TSAs, Poland $(0.8 \%)$, Italy $(0.5 \%)$, and the United States $(0.4 \%)$ reported relatively higher rates.

\section{Subgroup difference and meta-regression}

The differences between subgroups were statistically significant in the detection rate for serrated lesion between Asians and Caucasians $(P<0.001)$ but not between males and females $(P=0.077)$. The differences in rate of detection of SSPs between Asians and Caucasians was statistically significant $(P<0.001)$ but not between males and females $(P=0.786)(\vee$ Fig. 2$)$. Multivariate regression showed that study settings $(P=0.294$ 0.848 ), study period ( $P=0.444-0.870$ ), proportions of smokers $(P=0.721-0.879)$, definition of serrated lesions $(P=0.744)$, and study quality $(P=0.383-0.995)$ were not the source of heterogeneity observed in the present analysis ( $\triangleright$ Table 3 ). 
- Table 1b Characteristics of included studies $(\mathrm{N}=17)$.

\begin{tabular}{|c|c|c|c|c|c|c|c|c|c|c|}
\hline Study & Setting & $\begin{array}{l}\text { Detec- } \\
\text { tion } \\
\text { method }\end{array}$ & $\begin{array}{l}\text { Smoker } \\
\text { propor- } \\
\text { tion }\end{array}$ & $\begin{array}{l}\text { Routine vs } \\
\text { opportu- } \\
\text { nistic }\end{array}$ & $\begin{array}{l}\text { Defini- } \\
\text { tion_SL }\end{array}$ & $\begin{array}{l}\text { Defini- } \\
\text { tion_lo- } \\
\text { cation }\end{array}$ & SL (\%) & HP (\%) & SSP (\%) & TSA (\%) \\
\hline Liang 2012 & 3 & 1 & NA & 1 & WHO & - & 20.6 & - & - & - \\
\hline Kahi 2011 & 2 & 1 & NA & 1 & WHO & a & 13.0 & - & - & - \\
\hline Hetzel 2010 & 3 & 1 & NA & 1 & - & a & - & 11.7 & 0.6 & - \\
\hline Abdeljaward 2015 & 2 & 1 & NA & 1 & WHO & a & 20.4 & - & 8.1 & 0.4 \\
\hline Sanaka 2014 & 3 & 1 & NA & 1 & - & a & - & - & 1.8 & - \\
\hline Ross 2015 & 2 & 1 & NA & 1 & - & - & - & - & 8.2 & - \\
\hline Pуо 2017 & 3 & 1 & 28.4 & 1 & WHO & b & - & - & 0.5 & 0.6 \\
\hline Min 2012 & 2 & 1 & NA & 1 & WHO & a & 11.9 & - & - & - \\
\hline Kim 2014 & 3 & 1 & $\begin{array}{l}59.7^{1} \\
65.1^{2}\end{array}$ & 1 & WHO & a & 15.1 & 14.7 & 0.5 & 0.1 \\
\hline Lee 2013 & 3 & 1 & NA & 1 & WHO & $\mathrm{a}$ & 11.3 & - & - & - \\
\hline Wijkerslooth 2013 & 2 & 1 & NA & 1 & WHO & a & 12.3 & - & - & - \\
\hline Hazewinkel 2014 & 2 & 1 & NA & 1 & WHO & a & 27.2 & 23.8 & 4.8 & 0.1 \\
\hline Grobbee 2017 & 2 & 1 & NA & 1 & - & - & - & 12.7 & 3.0 & - \\
\hline Leung 2012 & 3 & 1 & NA & 1 & WHO & b & 21.4 & - & - & - \\
\hline Chang 2017 & 3 & 1 & 20.1 & 1 & WHO & - & - & 1.9 & 1.4 & - \\
\hline Buda 2012 & 2 & 1 & NA & 1 & WHO & - & - & 4.6 & 2.3 & 0.5 \\
\hline ljspeert 2016 & 2 & 1 & NA & 1 & WHO & a & 26.6 & - & 2.2 & 0.8 \\
\hline \multicolumn{11}{|c|}{$\begin{array}{l}\text { Setting: } 1=\text { national screening program, } 2=\text { multiple centers, } 3=\text { single } \\
\text { hospital/site; Detection method: } 1=\text { colonoscopy, } 2=\text { Sigmoidoscopy; Routine vs. opportunistic: } 1=\text { rountine, } \\
2=\text { opportunistic; Screening vs. surveillance: } 1=\text { Screening, } 2=\text { = Screening and surveillance. } \\
\text { NA, not available } \\
\text { WHO: Serrated lesions (SLs) were classified according to WHO criteria as hyperplastic polyps (HP), sessile serrated polyp (SSP) without cytologic dysplasia, SSP with } \\
\text { cytologic dysplasia (SSP-CD), traditional serrated adenoma (TSA) with and without conventional dysplasia, and serrated polyps unclassified; a: The proximal colon } \\
\text { was defined as proximal to the splenic flexure; b: The proximal colon was defined as proximal to transverse colon. } \\
1 \text { Adenoma group } \\
2 \text { Serrated lesions }\end{array}$} \\
\hline
\end{tabular}

\section{Sensitivity analysis and publication bias}

Sensitivity analysis showed no significant changes in the results after excluding each of the studies (Supplementary Fig.10). This indicated that the estimation for serrated lesions, SSPs, and TSAs was stable and robust. The funnel plots are shown in Supplementary Fig. 11. Publication bias was not significant for the results with serrated lesions $(P=0.902)$, SSPs $(P=0.087)$, and TSAs $(P>0.999)$ based on Begg's statistical tests.

\section{Discussion}

\section{Summary of major findings}

This was a systematic review and meta-analysis of 17 studies involving 129,001 average-risk individuals undergoing CRC screening with colonoscopy. The detection rates for serrated lesions and their different subtypes were estimated. The difference in detection rates between groups of different genders, ethnicities, and anatomical locations was also tested. The major findings are as follows. The overall detection rates for serrated lesions, SSPs, and TSAs were $19.0 \%, 2.5 \%$. and $0.3 \%$, respectively; 2) The detection rate for serrated lesions was higher in male than in female subjects $(22.0 \%$ vs $14.0 \%)$, and in Caucasians than Asians (23.6\% vs $14.7 \%$ ). The detection rate for SSPs was higher among Caucasians than Asians ( $2.9 \%$ vs $0.07 \%$ ), but similar between male and female individuals ( $2.9 \%$ vs $2.4 \%$ ). The detection rates estimated were not significantly affected by study settings, study periods, proportion of smokers, definitions of serrated lesions, study quality, or publication bias.

\section{Relationship to literature and explanations of findings}

The wide range of detection rates for serrated lesions could be accounted for by interobserver variability among endoscopists and pathologists caused by the variation in experiences and procedure-related factors. Serrated lesions are difficult to visualize during endoscopy and SSPs might be misclassified as "benign" HPs by colonoscopist. There is growing evidence that 
- Table2 Quality assessment of included studies based on the Newcastle-Ottawa Scale.

\begin{tabular}{|c|c|c|c|c|c|c|c|}
\hline Study & $\begin{array}{l}\text { Representa- } \\
\text { tiveness of } \\
\text { the sample }\end{array}$ & $\begin{array}{l}\text { Ascertain- } \\
\text { ment of } \\
\text { the expo- } \\
\text { sure }\end{array}$ & $\begin{array}{l}\text { Ascertain- } \\
\text { ment of } \\
\text { the out- } \\
\text { come }\end{array}$ & $\begin{array}{l}\text { Ascertainment of } \\
\text { the outcome } \\
\text { (quality control) }^{1}\end{array}$ & $\begin{array}{l}\text { Control for the most } \\
\text { important factor } \\
\text { (age or gender) }{ }^{2}\end{array}$ & $\begin{array}{l}\text { Control } \\
\text { any addi- } \\
\text { tional fac- } \\
\text { tor }^{3}\end{array}$ & $\begin{array}{l}\text { Total } \\
\text { Score }\end{array}$ \\
\hline Hetzel 2010 & 0 & 0 & 1 & 0 & 2 & 2 & 5 \\
\hline Kahi 2011 & 1 & 1 & 1 & 0 & 0 & 2 & 5 \\
\hline Buda 2012 & 1 & 1 & 1 & 1 & 2 & 1 & 7 \\
\hline Leung 2012 & 0 & 1 & 1 & 1 & 1 & 1 & 5 \\
\hline Liang 2012 & 0 & 0 & 1 & 1 & 0 & 0 & 2 \\
\hline Min 2012 & 1 & 1 & 1 & 1 & 2 & 1 & 7 \\
\hline Lee 2013 & 0 & 1 & 1 & 1 & 1 & 1 & 5 \\
\hline Wijkerslooth 2013 & 1 & 1 & 1 & 1 & 2 & 0 & 6 \\
\hline Hazewinkel 2014 & 1 & 1 & 1 & 1 & 2 & 1 & 7 \\
\hline Kim 2014 & 0 & 1 & 1 & 1 & 2 & 1 & 6 \\
\hline Sanaka 2014 & 0 & 1 & 1 & 1 & 1 & 1 & 5 \\
\hline Abdeljaward 2015 & 1 & 1 & 1 & 0 & 0 & 1 & 4 \\
\hline Ross 2015 & 1 & 1 & 1 & 1 & 1 & 1 & 6 \\
\hline Ijspeert 2016 & 1 & 0 & 1 & 1 & 2 & 1 & 6 \\
\hline Chang 2017 & 0 & 1 & 1 & 1 & 0 & 0 & 3 \\
\hline Grobbee 2017 & 1 & 0 & 1 & 1 & 1 & 1 & 5 \\
\hline Pyo 2017 & 0 & 1 & 1 & 1 & 2 & 0 & 5 \\
\hline
\end{tabular}

performance variability during colonoscopy has a great impact on detecting serrated lesions [33]. A study by Kahi et al among endoscopists reported that the rate of detection of proximal serrated lesions varied from $1 \%$ to $18 \%$ [13]. Another study by de Wijkerslooth et al. found a similar variable detection rate of $6 \%$ to $22 \%$ [11]. Therefore, some researchers proposed the serrated lesion detection rate as a performance indicator similar to the adenoma detection rate, to ensure adequate protection by CRC screening [34]. Also, there could be high interobserver variability in the ability to differentiate SSPs from HPs among different pathologists. This is largely due to the observation that some serrated lesions have features of both HPs and SSPs, and there is no universal consensus about the minimum number of SSP features required for making a diagnosis of SSP [35].

This study found that the detection rate for serrated lesions and SSPs was lower in Asians than in Caucasians. The reasons behind this disparity can be multifactorial and remain unclear. Differences in lifestyle factors between the two populations might account for the difference in detection rate for serrated lesions and SSPs. For instance, a lower intake of dietary fat was reported in the East than in the West probably due to consumption of more meat in the latter population [36]. A recent cohort study involving more than 140,000 participants with two dec- ades of follow-up concluded that tobacco smoking, obesity, and alcohol drinking were more strongly associated with serrated lesions than with other colorectal neoplasia, whereas physical activity as well as folate and calcium intake were inversely associated with other colorectal neoplasia but not with serrated lesions [37]. A meta-analysis including 43 studies showed that serrated lesion risk was associated with seven different lifestyle factors, including smoking, alcohol drinking, body fatness, dietary pattern, physical activity, medication of nonsteroidal antiinflammatory drugs, and hormone replacement therapy. The researchers concluded that serrated lesions were associated with smoking (risk ratio, $R R=2.5)$, alcohol drinking $(R R=1.3)$, obesity $(R R=1.4)$, and high fat or red meat intake. Another interesting finding was that the associations for tobacco smoking and alcohol drinking, but not body fatness, were stronger for SSPs than HPs [38]. Gut microbiota also may be related. There is evidence showing that ethnic variation in SSP was inversely correlated with variation in prevalence of Helicobacter pylori gastritis in the ethnic groups [39].

In addition to lifestyle factors, the difference in detection rate for serrated lesions between Caucasians and Asians also may be attributable to genetic variations. In terms of the genetics of the serrated pathway, BRAF (B-Raf proto-oncogene, ser- 


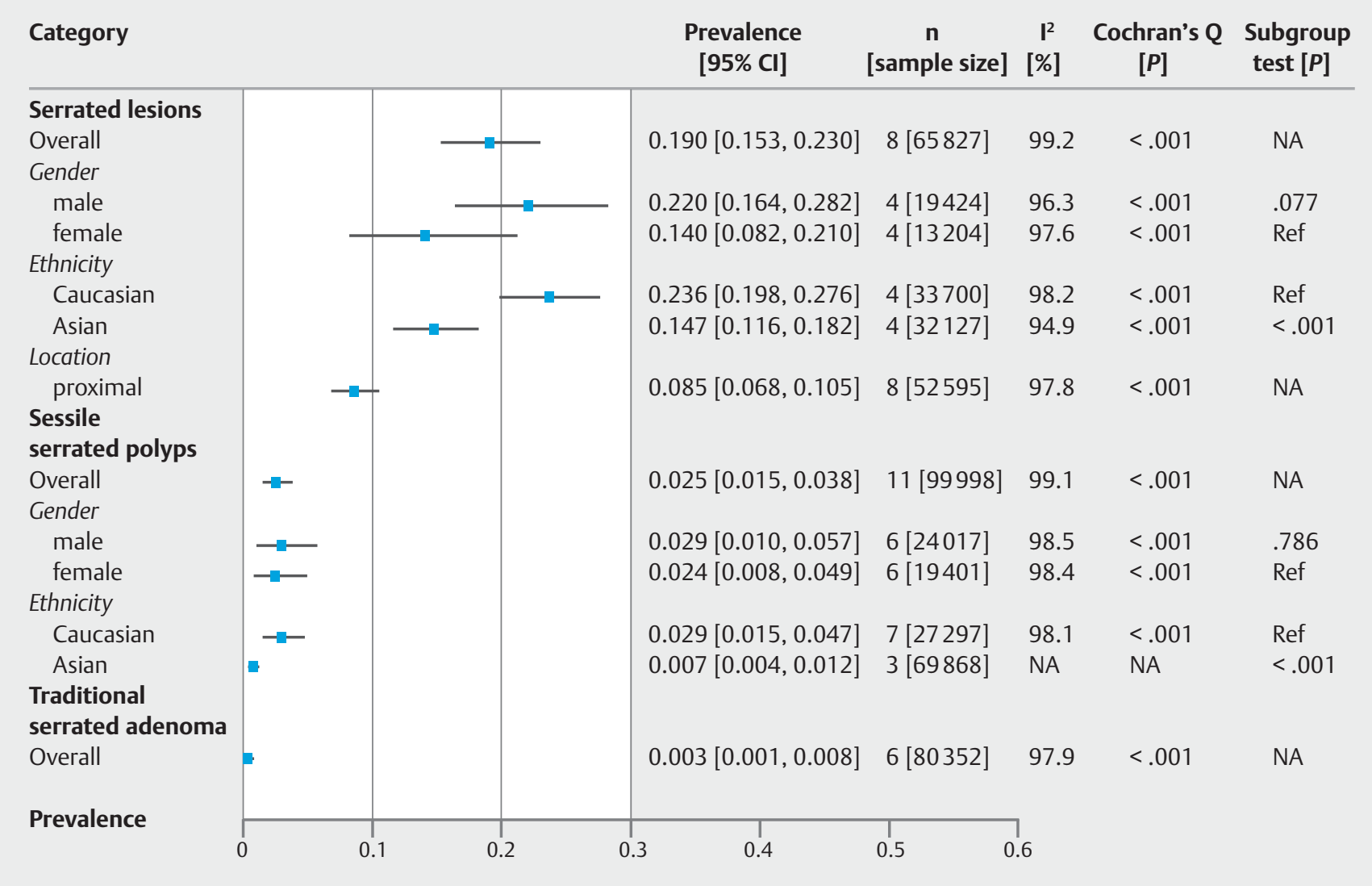

Fig. 2 Detection rates for serrated lesions, sessile serrated polyps, and traditional serrated adenomas.

ine/threonine Kinase) mutation, KRAS (Kirsten rat sarcoma 2 viral oncogene homolog) mutation and CIMP (CpG island methylator phenotype) play a crucial role. According to their status as a precursor lesion, SSPs demonstrate a high level of BRAF mutation, CIMP [40]. The rate of BRAF mutation has been reported to be $62.1 \%$ to $90 \%$ in SSPs and $27 \%$ to $55 \%$ in TSAs [40-43]. One Chinese study reported a BRAF V600E mutation rate of $14.3 \%$ in SSP, which is lower than that in the Western population [44]. One Korean study reported that BRAF V600E mutations were found in $43.5 \%$ to $58.3 \%$ of TSAs [45]. Early molecular alterations in serrated lesions are BRAF and KRAS mutations [46]. KRAS and BRAF are cellular signaling molecules that mediate responses to extracellular signals. O'Brien and colleagues also demonstrated that CIMP was more prevalent in larger and more proximally located lesions [47].

The detection rate for serrated lesions is higher in males than females as hormones may play a role in this difference. Studies have suggested that estrogen exposure or hormone replacement therapy may be protective against the risk for CRC, and similarly for serrated lesions [48]. The Women's Health Initiative clinical trial demonstrated a $40 \%$ decreased risk of CRC in postmenopausal women taking hormone replacement therapy, which may contribute to lower risk of serrated lesions [48]. The lower detection rate may also be due to the under-detection of serrated lesions in females. For instance, it was shown that female gender was associated with the development of in- terval CRC [49]. The lower detection rate could be attributed to the fact that colonoscopy may be more difficult to perform in women, given their longer transverse colon than that of men [50].

\section{Study limitations}

This study examined the overall detection rate for serrated lesions in average-risk populations, and the detection rates may act as references for high-quality CRC screening programs. The overall quality of the articles was good as assessed by NOS. Subgroup analysis and multivariate meta-regression were performed to identify the possible source of heterogeneity. Nevertheless, there were several limitations. First and foremost, there were only 17 studies included due to the paucity of data in the literature. Therefore, some additional confounding factors could not be studied, including dietary factors, obesity, and the level of physical activity. In addition, figures from some countries were represented by estimates from studies in a single center. The comparison of serrated lesion detection rates between races was generally not conducted within studies but rather between studies. This may have introduced additional potential bias since factors other than race may differ between the study populations. Moreover, as studies of detection rate for serrated lesions were only available from the past decade, time-trend detection rate analysis of the serrated lesions was 
- Table 3 Results of multivariate regression.

\begin{tabular}{|c|c|c|c|c|c|c|}
\hline & \multicolumn{2}{|c|}{ Serrated lesions } & \multicolumn{2}{|l|}{ SSP } & \multicolumn{2}{|l|}{ TSA } \\
\hline & Coefficient & P value & Coefficient & P value & Coefficient & $P$ value \\
\hline Overall & 0.159 & 0.383 & 0.021 & 0.693 & 0.009 & 0.740 \\
\hline \multicolumn{7}{|l|}{ Setting } \\
\hline - National screening program/large cohort study & \multicolumn{2}{|l|}{ - } & \multicolumn{2}{|l|}{-} & \multicolumn{2}{|l|}{-} \\
\hline - Multiple centers & \multicolumn{2}{|l|}{ Reference } & \multicolumn{2}{|l|}{ Reference } & \multicolumn{2}{|l|}{-} \\
\hline - Single hospital/site & -0.204 & 0.848 & -0.037 & 0.294 & \multicolumn{2}{|l|}{-} \\
\hline \multicolumn{7}{|l|}{ Study period ${ }^{1}$} \\
\hline . 2006-2010 & \multicolumn{2}{|l|}{ Reference } & \multicolumn{2}{|l|}{ Reference } & \multicolumn{2}{|l|}{-} \\
\hline . 2011-2014 & 0.012 & 0.870 & 0.020 & 0.444 & - & \\
\hline \multicolumn{7}{|l|}{ Smoking proportion } \\
\hline . $<50 \%$ & \multicolumn{2}{|l|}{-} & -0.015 & 0.689 & -0.009 & 0.762 \\
\hline - $\geq 50 \%$ & \multicolumn{2}{|l|}{ Reference } & \multicolumn{2}{|l|}{ Reference } & \multicolumn{2}{|l|}{ Reference } \\
\hline NM & 0.059 & 0.721 & 0.007 & 0.879 & -0.002 & 0.929 \\
\hline \multicolumn{7}{|l|}{ Definition } \\
\hline - WHO & \multicolumn{2}{|l|}{-} & -0.014 & 0.744 & \multicolumn{2}{|l|}{-} \\
\hline - NM & \multicolumn{2}{|l|}{-} & \multicolumn{2}{|l|}{ Reference } & \multicolumn{2}{|l|}{ - } \\
\hline \multicolumn{7}{|l|}{ Study quality (NOS score) } \\
\hline.$\leq 5$ & 0.159 & 0.383 & 0.019 & 0.495 & -0.003 & 0.900 \\
\hline . $>5$ & \multicolumn{2}{|l|}{ Reference } & \multicolumn{2}{|l|}{ Reference } & \multicolumn{2}{|l|}{ Reference } \\
\hline
\end{tabular}

not feasible. The period effect in the detection rate for these lesions is yet to be explored.

\section{Implications}

To enhance the success of CRC screening by preventing interval cancers, it is important to determine detection rates for serrated lesions and establish serrated lesion detection rates as quality indicators for colonoscopy. The pooled detection rate estimates in this study can be used as a reference for establishing CRC screening programs. For example, the overall detection rates with $95 \% \mathrm{Cl}$ for serrated lesions, SSPs, and TSAs were $19.0 \%, 95 \% \mathrm{Cl}=15.3 \%-23.0 \%, 2.5 \%, 95 \% \mathrm{Cl}=1.5 \%-3.8 \%$, and $0.3 \%, 95 \% \mathrm{Cl}=0.1 \%-0.8 \%$, respectively. The detection rates for serrated lesions in future CRC screening programs are likely to fall into these ranges. In addition to gender and ethnicity, the detection rates may be affected by the quality of colonoscopy and histological categorization. Future research should evaluate performance-related factors associated with detection of serrated lesions so as to inform strategies to enhance the detection rate for serrated lesions.

\section{Conclusion}

The overall detection rate for serrated lesions, SSPs, and TSAs was estimated in this meta-analysis (Supplementary Fig.1). The detection rate for serrated lesions was higher in male than female subjects, and in Caucasians than in Asians. The detection rate for SSPs was higher among Caucasians than Asians, but similar between male and female individuals. Study settings, study periods, proportion of smokers, definitions of serrated lesions, study quality, and publication bias did not affect the estimation.

\section{Acknowledgments}

The abstract of this study was presented in The International Digestive Disease Forum (IDDF) on June 8, 2019 in Hong Kong.

\section{Competing interests}

The authors declare that they have no conflict of interest. 


\section{Reference}

[1] World Health Organization. Cancer. 2018. Available at (Accessed April 15, 2019): https://www.who.int/news-room/fact-sheets/detail/cancer

[2] Zauber AG, Winawer S], O'Brien M] et al. Colonoscopic polypectomy and long-term prevention of colorectal-cancer deaths. N Engl J Med 2012; 366: 687-696

[3] Harewood GC, Lieberman DA. Colonoscopy practice patterns since introduction of medicare coverage for average-risk screening. Clin Gastroenterol Hepatol 2004; 2: 72-77

[4] Lieberman DA, Weiss DG, Harford WV et al. Five-year colon surveillance after screening colonoscopy. Gastroenterology 2007; 133 : 1077-1085

[5] Robertson DJ, Greenberg ER, Beach M et al. Colorectal cancer in patients under close colonoscopic surveillance. Gastroenterology 2005; 129: 34-41

[6] Arain MA, Sawhney M, Sheikh S et al. CIMP status of interval colon cancers: another piece to the puzzle. Am J Gastroenterol 2010; 105: 1189-1195

[7] Leggett B, Whitehall V. Role of the serrated pathway in colorectal cancer pathogenesis. Gastroenterology 2010; 138: 2088-2100

[8] Bosman FT, Carneiro F, Hruban RH et al. WHO Classification of digestive tumors: the fourth edition. World Health Organization; 2010

[9] World Health Organisation. Classification of Tumours of the Digestive Tract. Lyon: IARC Press; 2019

[10] Hetzel JT, Huang CS, Coukos JA et al. Variation in the detection of serrated polyps in an average risk colorectal cancer screening cohort. Am J Gastroenterol 2010; 105: 2656-2664

[11] de Wijkerslooth TR, Stoop EM, Bossuyt PM et al. Differences in proximal serrated polyp detection among endoscopists are associated with variability in withdrawal time. Gastrointest Endosc 2013; 77: 617-623

[12] Je IJ, van Doorn SC, van der Brug YM et al. The proximal serrated polyp detection rate is an easy-to-measure proxy for the detection rate for clinically relevant serrated polyps. Gastrointest Endosc 2015; 82: 870-877

[13] Kahi C], Hewett DG, Norton DL et al. Prevalence and variable detection of proximal colon serrated polyps during screening colonoscopy. Clin Gastroenterol Hepatol 2011; 9: 42-46

[14] Buda A, De Bona M, Dotti I et al. Prevalence of different subtypes of serrated polyps and risk of synchronous advanced colorectal neoplasia in average-risk population undergoing first-time colonoscopy. Clin Transl Gastroenterol 2012; 3: e6

[15] Abdeljawad K, Vemulapalli KC, Kahi C] et al. Sessile serrated polyp prevalence determined by a colonoscopist with a high lesion detection rate and an experienced pathologist. Gastrointest Endosc 2015; 81: $517-524$

[16] Moher D, Shamseer L, Clarke M et al. Preferred reporting items for systematic review and meta-analysis protocols (PRISMA-P) 2015 statement. Syst Rev 2015; 4: 1

[17] Wells GA, Peterson J, Welch V et al. The Newcastle-Ottawa Scale (NOS) for assessing the quality of nonrandomised studies in metaanalyses. In: http://www.ohri.ca/programs/clinical_epidemiology/ oxford.asp

[18] Wong MC, Huang J, Huang JL et al. Global prevalence of colorectal neoplasia: a systematic review and meta-analysis. Clin Gastroenterol Hepatol 2019: doi:10.1016/j.cgh.2019.07.016

[19] Huang JLW, Wang YH, Jiang JY et al. The association between distal findings and proximal colorectal neoplasia: a systematic review and meta-Analysis. Am J Gastroenterol 2017; 112: 1234-1245

[20] Nyaga VN, Arbyn M, Aerts M. Metaprop: a Stata command to perform meta-analysis of binomial data. Arch Public Health 2014; 72: 39
[21] Grobbee EJ, Wieten E, Hansen BE et al. Fecal immunochemical testbased colorectal cancer screening: The gender dilemma. United European Gastroenterol J 2017; 5: 448-454

[22] Min YW, Lee JH, Lee SH et al. Prevalence of proximal colon serrated polyps in a population at average risk undergoing screening colonoscopy: a multicenter study. Clin Res Hepatol Gastroenterol 2012; 36: 604-608

[23] Liang J, Kalady MF, Appau K et al. Serrated polyp detection rate during screening colonoscopy. Colorectal Dis 2012; 14: 1323-1327

[24] Chang LC, Shun CT, Hsu WF et al. Fecal immunochemical test detects sessile serrated adenomas and polyps with a low level of sensitivity. Clin Gastroenterol Hepatol 2017; 15: 872-879 e871

[25] Hazewinkel Y, de Wijkerslooth TR, Stoop EM et al. Prevalence of serrated polyps and association with synchronous advanced neoplasia in screening colonoscopy. Endoscopy 2014; 46: 219-224

[26] JEG IJ, Bevan R, Senore C et al. Detection rate for serrated polyps and serrated polyposis syndrome in colorectal cancer screening cohorts: a European overview. Gut 2017; 66: 1225-1232

[27] Ross WA, Thirumurthi S, Lynch PM et al. Detection rates of premalignant polyps during screening colonoscopy: time to revise quality standards? Gastrointest Endosc 2015; 81: 567-574

[28] Sanaka MR, Gohel T, Podugu A et al. Adenoma and sessile serrated polyp detection rates: variation by patient sex and colonic segment but not specialty of the endoscopist. Dis Colon Rectum 2014; 57 : 1113-1119

[29] Pyo JH, Ha SY, Hong SN et al. Identification of risk factors for sessile and traditional serrated adenomas of the colon by using big data analysis. J Gastroenterol Hepatol 2018; 33: 1039-1046

[30] Kim HY, Kim SM, Seo JH et al. Age-specific prevalence of serrated lesions and their subtypes by screening colonoscopy: a retrospective study. BMC Gastroenterol 2014; 14: 82

[31] Lee CK, Kim YW, Shim JJ et al. Prevalence of proximal serrated polyps and conventional adenomas in an asymptomatic average-risk screening population. Gut Liver 2013; 7: 524-531

[32] Leung WK, Tang V, Lui PC. Detection rates of proximal or large serrated polyps in Chinese patients undergoing screening colonoscopy. J Dig Dis 2012; 13: 466-471

[33] Rex DK. Serrated Polyps in the Colon. Gastroenterol Hepatol (N Y) 2014; 10: 671-674

[34] Schramm C, Janhsen K, Hofer JH et al. Detection of clinically relevant serrated polyps during screening colonoscopy: results from seven cooperating centers within the German colorectal screening program. Endoscopy 2018; 50: 993-1000

[35] Wong NA, Hunt LP, Novelli MR et al. Observer agreement in the diagnosis of serrated polyps of the large bowel. Histopathology 2009; 55: 63-66

[36] Popkin BM, Adair LS, Ng SW. Global nutrition transition and the pandemic of obesity in developing countries. Nutr Rev 2012; 70: 3-21. doi:10.1111/j.1753-4887.2011.00456.x

[37] He X, Wu K, Ogino S et al. Association between risk factors for colorectal cancer and risk of serrated polyps and conventional adenomas. Gastroenterology 2018; 155: 355-373 e318

[38] Bailie L, Loughrey MB, Coleman HG. Lifestyle risk factors for serrated colorectal polyps: a systematic review and meta-analysis. Gastroenterology 2017; 152: 92-104

[39] Sonnenberg A, Turner KO, Genta RM. The ethnic distribution of sessile serrated polyps in the United States is inversely associated with Helicobacter pylori prevalence. Colorectal Dis 2017; 19: 996-1002

[40] Jass JR, Baker K, Zlobec I et al. Advanced colorectal polyps with the molecular and morphological features of serrated polyps and adenomas: concept of a 'fusion' pathway to colorectal cancer. Histopathology 2006; 49: 121-131 
[41] Rosenberg DW, Yang S, Pleau DC et al. Mutations in BRAF and KRAS differentially distinguish serrated versus non-serrated hyperplastic aberrant crypt foci in humans. Cancer Res 2007; 67: 3551-3554

[42] Mohammadi M, Kristensen MH, Nielsen HJ et al. Qualities of sessile serrated adenoma/polyp/lesion and its borderline variant in the context of synchronous colorectal carcinoma. J Clin Pathol 2012; 65: 924-927

[43] Fu B, Yachida S, Morgan R et al. Clinicopathologic and genetic characterization of traditional serrated adenomas of the colon. Am J Clin Pathol 2012; 138: 356-366

[44] Qiu Y, Fu X, Zhang W et al. Prevalence and molecular characterisation of the sessile serrated adenoma in a subset of the Chinese population. J Clin Pathol 2014; 67: 491-498

[45] Kim MJ, Lee EJ, Suh JP et al. Traditional serrated adenoma of the colorectum: clinicopathologic implications and endoscopic findings of the precursor lesions. Am J Clin Pathol 2013; 140: 898-911
[46] Rajagopalan H, Bardelli A, Lengauer $\mathrm{C}$ et al. Tumorigenesis: RAF/RAS oncogenes and mismatch-repair status. Nature 2002; 418: 934

[47] O'Brien M], Yang S, Clebanoff JL et al. Hyperplastic (serrated) polyps of the colorectum: relationship of $\mathrm{CpG}$ island methylator phenotype and K-ras mutation to location and histologic subtype. Am J Surg Pathol 2004; 28: 423-434

[48] Slattery ML, Potter JD, Curtin K et al. Estrogens reduce and withdrawal of estrogens increase risk of microsatellite instability-positive colon cancer. Cancer Res 2001; 61: 126-130

[49] Lee YM, Huh KC. Clinical and biological features of interval colorectal cancer. Clin Endosc 2017; 50: 254-260

[50] Saunders BP, Fukumoto M, Halligan S et al. Why is colonoscopy more difficult in women? Gastrointest Endosc 1996; 43: 124-126 